\title{
Regulation of intestinal SGLT1 by catestatin in hyperleptinemic type 2 diabetic mice
}

\author{
Jessica A Dominguez Rieg ${ }^{1,2}$, Venkat R Chirasani ${ }^{3}$, Hermann Koepsell ${ }^{4}$, Sanjib Senapati ${ }^{3}$, Sushil K Mahata ${ }^{2,5}$ and \\ Timo Rieg ${ }^{2,5}$
}

The small intestine is the major site for nutrient absorption that is critical in maintenance of euglycemia. Leptin, a key hormone involved in energy homeostasis, directly affects nutrient transport across the intestinal epithelium. Catestatin (CST), a 21-amino acid peptide derived from proprotein chromogranin A, has been shown to modulate leptin signaling. Therefore, we reasoned that leptin and CST could modulate intestinal $\mathrm{Na}^{+}$-glucose transporter 1 (SGLT1) expression in the context of obesity and diabetes. We found that hyperleptinemic $d b / d b$ mice exhibit increased mucosal mass, associated with an enhanced proliferative response and decreased apoptosis in intestinal crypts, a finding absent in leptin-deficient ob/ob mice. Intestinal SGLT1 abundance was significantly decreased in hyperleptinemic but not leptin-deficient mice, indicating leptin regulation of SGLT1 expression. Phlorizin, a SGLT1/2 inhibitor, was without effect in an oral glucose tolerance test in $d b / d b$ mice. The alterations in architecture and SGLT1 abundance were not accompanied by changes in the localization of intestinal alkaline phosphatase, indicating intact differentiation. Treatment of $d b / d b$ mice with CST restored intestinal SGLT1 abundance and intestinal turnover, suggesting a cross-talk between leptin and CST, without affecting plasma leptin levels. Consistent with this hypothesis, we identified structural homology between CST and the ABloop of leptin and protein-protein docking revealed binding of CST and leptin with the Ig-like binding site-III of the leptin receptor. In summary, downregulation of SGLT1 in an obese type 2 diabetic mouse model with hyperleptinemia is presumably mediated via the short form of the leptin receptor and reduces overt hyperglycemia.

Laboratory Investigation (2016) 96, 98-111; doi:10.1038/labinvest.2015.129; published online 9 November 2015

Obesity and diabetes are the two largest health challenges in the twenty-first century, and both are associated with an increased risk and incidence of gastrointestinal disorders such as gastroparesis, slowed gastrointestinal transit time, and constipation. ${ }^{1,2}$ The small intestine is involved in delivering dietary sugars to the systemic circulation, the rate of which has a major impact on regulating blood glucose concentration. Under basal conditions, glucose is actively transported across the apical membrane of the enterocyte via the $\mathrm{Na}^{+}$-glucose cotransporter-1 (SGLT1) ${ }^{3}$ and is passively transported across the basolateral membrane via the glucose transporter-2 (GLUT2). ${ }^{4}$ These sugar transporters are highly regulated by changing their activity levels, localization within the cell, and by regulation of encoding genes. In addition, they can be controlled by gastrointestinal hormones such as glucagon-like peptide-2 (GLP-2), ${ }^{5}$ cholecystokinin(CCK), ${ }^{6}$ and leptin. ${ }^{7}$
Leptin, a $16 \mathrm{kDa}$ adipocyte-derived hormone, is critically involved in energy intake and expenditure. ${ }^{8}$ Leptin exerts its biological actions via six distinct leptin receptors (LEPRa to LEPRf) generated by alternative splicing and proteolytic cleavage. $^{9-11}$ These isoforms are divided into three classes: short (LEPRa, c, d, and f), long (LEPRb), and secreted (LEPRe) forms. LEPRs are abundant in the small and large intestine, supporting the idea that leptin could directly affect nutrient transport across the intestinal epithelium. ${ }^{7}$ The long form, LEPRb, has been shown to be crucial for leptin action; however, the function of the short forms of the receptor is less clear. Of note, LEPRa was found to be the most abundant as well as the most ubiquitously expressed isoform. ${ }^{12-15}$ The absence of leptin signaling in leptin-deficient $o b / o b$ mice or impaired leptin signaling in LEPRb-deficient $d b / d b$ mice promotes hyperphagia and decreased energy expenditure,

Department of Basic Sciences, Bastyr University California, San Diego, CA, USA: ${ }^{2}$ VA San Diego Healthcare System, San Diego, CA, USA; ${ }^{3}$ Department of Biotechnology, Institute of Technology Madras, Chennai, India; ${ }^{4}$ Department of Molecular Plant Physiology and Biophysics, Julius-von-Sachs-Institute, University of Würzburg, Würzburg, Germany and ${ }^{5}$ Division of Nephrology/Hypertension, Department of Medicine, University of California, San Diego, La Jolla, CA, USA

Correspondence: T Rieg, MD, Division of Nephrology/Hypertension, Department of Medicine, University of California San Diego and VA San Diego Healthcare System, 3350 La Jolla Village Drive (9151), San Diego, CA 92161, USA.

E-mail: trieg@ucsd.edu

Received 5 May 2015; revised 10 September 2015; accepted 24 September 2015 
making them commonly used animal models for obesity and type 2 diabetes mellitus. ${ }^{16}$ Importantly, both models mimic the gastrointestinal dysfunction seen in obese diabetic patients. It was shown that in $d b / d b$ mice, the defective LEPRb isoform is replaced by LEPRa, ${ }^{9,17}$ and generation of a LEPRa knockout mouse confirmed that LEPRa is indeed required for leptin signaling. ${ }^{18}$ Leptin signaling appears to play a critical role in gastrointestinal functions and nutrient absorption. ${ }^{19,20}$ However, the role of leptin signaling in regulation of nutrient transporters such as SGLT1 in the context of obesity and type 2 diabetes has remained elusive.

Catestatin (CST) was initially identified as a physiological brake for catecholamine secretion. ${ }^{21-23}$ Recently, it has been shown that CST interacts with leptin receptors. ${ }^{24}$ The aim of the present study was to investigate the role of leptin and its receptors (LEPRa and LEPRb) on intestinal morphology and expression of SGLT1 in leptin-deficient $o b / o b$ mice and LEPRb-deficient $d b / d b$ mice and its regulation by CST. We found that leptin-induced downregulation of intestinal SGLT1 is mediated by the short form of the leptin receptor, LEPRa. In addition, our data provide initial evidence that CST may bind to the leptin receptor and modulate SGLT1 abundance and intestinal turnover.

\section{MATERIALS AND METHODS Animals}

Animal experiments were conducted according to protocols reviewed and approved by the institutional animal care and use committee of the Veterans Affairs San Diego Healthcare System. Homozygous $d b / d b$ mice (697, Jackson Laboratories, Bar Harbor, ME, USA) were used as a hyperleptinemic obese type 2 diabetic model, and littermate heterozygote $\mathrm{db} /{ }^{+}$mice served as controls (db/con). Homozygous ob/ob mice (632, Jackson Laboratories) were used as a leptin-deficient obese type 2 diabetic model, and littermate heterozygote $\mathrm{ob} /{ }^{+}$ mice served as controls (ob/con). The generation and phenotype of SGLT1 knockout mice $\left(\right.$ Sglt $\left.^{-1-}\right)$ has been described previously. ${ }^{3}$ Adult male (between 3 and 6 months old) mice were used for all experiments. Mice were housed in the same animal room with a 12:12 h light/dark cycle and free access to food (7001, Harlan Teklad, Indianapolis, IN, USA) and tap water. Sglt $1^{-1-}$ mice were kept on low-glucose diet to prevent glucose/galactose malabsorption and subsequent diarrhea and death due to the absence of SGLT1.

\section{Oral Glucose Tolerance Tests (OGTT)}

Animals were fasted overnight before glucose challenge. For OGTT, glucose was administered $(2 \mathrm{~g} / \mathrm{kg}, 1 \%$ of body weight (bw) via oral gavage) without or with phlorizin $(0.5 \mathrm{~g} / \mathrm{kg})$. Blood glucose was determined (measured via tail snip, Ascensia Elite XL) at $0,15,30,45,60$, and $120 \mathrm{~min}$. To obtain the area under curve (AUC), the blood glucose response profiles corresponding to each animal were determined using as reference each individual baseline $(t=0)$ blood glucose measurement or the lowest point of the curve.

\section{Morphological Analysis of the Intestine}

Small intestine and colon were collected from each animal and measured in length $(\mathrm{cm})$ before flushing fecal contents with ice-cold phosphate-buffered saline (PBS). Afterwards, tissue was fixed overnight in $4 \%$ paraformaldehyde, paraffin embedded, and sectioned at 4-6 $\mu \mathrm{m}$. After deparaffinization and rehydration, sections were either stained with hematoxylin and eosin (H\&E; for morphometry and apoptosis quantification), stained for proliferating cell nuclear antigen (PCNA; for proliferation quantification), stained for cleaved caspase-3 (for apoptosis quantification), or stained with substrate to localize endogenous intestinal alkaline phosphatase (to assess differentiation).

For immunohistochemical staining of PCNA and cleaved caspase-3, sections were incubated in $3 \% \mathrm{H}_{2} \mathrm{O}_{2}$ for $10 \mathrm{~min}$, heated in Antigen Decloaker (Biocare Medical, Concord, CA, USA) for $45 \mathrm{~min}$, blocked with $20 \%$ normal goat serum (Vector Laboratories, Burlingame, CA, USA), and then incubated with either mouse monoclonal PCNA antibody (1:100; Invitrogen, Camarillo, CA, USA) or rabbit polyclonal cleaved caspase- 3 antibody (1:100; Cell Signaling Technology, Beverly, MA, USA) for $1 \mathrm{~h}$ at room temperature. Sections were then incubated with either goat anti-mouse biotinylated secondary antibody (PCNA, 1:200; Vector Laboratories) or goat anti-rabbit biotinylated secondary antibody (cleaved caspase-3, 1:200; Vector Laboratories) for $30 \mathrm{~min}$ at room temperature. Vectastain Elite $\mathrm{ABC}$ reagent (Vector Laboratories) was then applied, followed by diaminobenzidine as substrate. Sections were counterstained with hematoxylin, dehydrated, and cover-slipped. For immunohistochemical analysis of differentiation, slides were incubated with Vector Red Alkaline Phophatase Substrate (Vector Laboratories) and then counterstained with hematoxylin, dehydrated, and cover-slipped according to the manufacturer's instructions.

In H\&E-stained jejunal sections, villus length and crypt depth were measured in 12-15 well-oriented crypt-villus units per animal. To determine apoptosis in the intestinal epithelium, apoptotic cells were quantified using (1) morphological criteria of cell shrinkage with condensed and fragmented nuclei and (2) number of cleaved caspase-3-positive cells. ${ }^{25}$ Apoptotic epithelial cells were quantified in 100 well-oriented contiguous crypts and 50 well-oriented villi per animal. Intestinal proliferation was determined by quantifying PCNA-positive cells in 100 consecutive crypts per animal. All counting was performed by a blinded investigator.

\section{Western Blot Analyses}

Intestinal mucosa was scraped and homogenized in buffer containing protease inhibitor cocktail $(250 \mathrm{mM}$ sucrose, $10 \mathrm{mM}$ triethanolamine, Sigma-Aldrich, St Louis, MO, USA and Roche Applied Science, Indianapolis, IN, USA, 
respectively) and Halt phosphatase inhibitor cocktail (Thermo Fisher Scientific, Waltham, MA, USA). ${ }^{26,27}$ The homogenate was centrifuged at $4000 \mathrm{~g}$ for $15 \mathrm{~min}$. Pellets were resuspended and used for western blotting. Equal lane loading $(20 \mu \mathrm{g})$ was achieved using a detergent-compatible protein assay (Bio-Rad, Richmond, CA, USA). Samples were resolved on $4-12 \%$ NuPAGE gels in MOPS buffer (Invitrogen, Carlsbad, CA, USA). Gel proteins were transferred to nitrocellulose membranes and incubated over night at $4{ }^{\circ} \mathrm{C}$ with rabbit-raised primary antibody against SGLT1 (1:2000). ${ }^{3}$ Horseradish peroxidase enzyme activity was detected via enhanced chemiluminescence (Amersham, Piscataway, NJ, USA). For verification of equal protein loading, the membrane was stripped $(0.2 \mathrm{~mol} / \mathrm{l} \mathrm{NaOH}$ for $5 \mathrm{~min})$ and reprobed with monoclonal anti- $\beta$-actin antibody (1:30 000; A2228, Sigma-Aldrich). Densitometric analysis was performed by ImageJ Software v1.48 (National Institutes of Health, Bethesda, MD, USA).

\section{Protein Localization via Immunofluorescent Staining}

Sections were deparaffinized, rehydrated, and incubated in $3 \% \mathrm{H}_{2} \mathrm{O}_{2}$ for $10 \mathrm{~min}^{26,28}$ Slides were then placed in citrate buffer for antigen retrieval and microwaved for $7 \mathrm{~min}$, incubated in $0.5 \%$ Triton-X for $15 \mathrm{~min}$, blocked with $1 \%$ BSA (Vector Laboratories), and then primary antibody (SGLT1, see previous section) was applied in a dilution of 1:100 in blocking buffer and incubated for $1 \mathrm{~h}$ at room temperature. The specificity of the SGLT1 antibody for immunofluorescence has previously been shown by the absence of a fluorescent signal in the intestine of Sglt $1^{-1-}$ mice. $^{3}$ Slides were then incubated with $0.1 \%$ Triton-X for $10 \mathrm{~min}$ and washed with PBS. The secondary antibody (Alexa Fluor 594-conjugated donkey anti-rabbit IgG; Life Technologies, Grand Island, NY, USA) was applied in a dilution of 1:200 in blocking buffer and incubated for $1 \mathrm{~h}$ at room temperature in the dark. The slides were washed with PBS before being mounted with ProLong Gold antifade reagent with 4',6-diamidino-2-phenylindole (Life Technologies). Slides were analyzed and pictures were taken on an Olympus IX81 Microscope.

\section{CST Modeling}

The NMR structure of human wild-type CST was downloaded from a protein data bank (PDB ID: 1LV4). ${ }^{29}$ Molecular dynamics (MD) simulation was carried out on this structure for 200 nanoseconds (ns) in water to generate an ensemble of conformations. The time-averaged structure of CST was considered for subsequent analysis. Out of the 20 NMR conformations of CST available in PDB (ID: 1LV4), the first conformation was selected as the default choice for MD simulations.

\section{Leptin Modeling}

The crystal structure of leptin with $2.4 \AA$ resolution was obtained from a PDB (ID: 1AX8). ${ }^{30}$ The crystal structure with
GLU at position 100 was changed to a wild-type residue, TRP, and a short energy minimization was carried out. The highly flexible AB-loop of leptin, which belongs to its binding site-III and is composed of residues THR 27-GLY 38, was missing from the crystal structure. Hence, we modeled and optimized the missing AB-loop using Modeller 9v10. ${ }^{31} \mathrm{MD}$ simulation was performed on the obtained structure in water for $200 \mathrm{~ns}$. Time-averaged structure of whole leptin was used for subsequent leptin-LEPR docking studies.

\section{Leptin Receptor Modeling}

The crystal structure of the leptin-binding domain (LBD) of the human LEPR with $1.95 \AA$ resolution was downloaded from a PDB (ID: 3V6O). ${ }^{32}$ Recently, mutational studies have shown that binding site-III of leptin interacts with the Ig-like domain of LEPR. ${ }^{33}$ However, there is no structural information of the Ig-like domain of LEPR. Hence, this domain was modeled and included with the LEPR crystal structure. Lack of a suitable template in the PDB prompted us to utilize the protein fold recognition approach (threading) to model the Ig-like domain of LEPR using the FUGUE server. ${ }^{34}$ The structure of LEPR with the LBD and Ig-like domain was simulated for $25 \mathrm{~ns}$ in water for structural refinement. The time-averaged structure was used for further docking analysis with leptin and CST.

\section{Molecular Dynamics Simulation Protocol}

All the simulations were carried out using Gromacs-4.5.5 simulation package using Amber99SB force field. ${ }^{35,36}$ The simulation systems were energy minimized for 1000 steps using conjugate gradient algorithm. The structures were solvated in a cubic periodic box of explicit water. Water molecules were described using TIP3P water model. A salt concentration of $150 \mathrm{mmol} / \mathrm{l}$ was maintained by adding a sufficient number of $\mathrm{Na}^{+}$and $\mathrm{Cl}^{-}$ions. The solvated systems were energy minimized extensively and further gradually heated to $300 \mathrm{~K}$ in a canonical ensemble. The solvent density was calibrated at $1 \mathrm{~atm}$ and $300 \mathrm{~K}$ under isobaric and isothermal conditions. The simulation systems were equilibrated in an isothermal-isobaric ensemble for 10 ns with a time step of 2 fs. Particle Mesh Ewald sum technique was used to treat the long-range electrostatic interactions with a real space cutoff of $1 \mathrm{~nm}$. SHAKE algorithm was used to constrain all bonds involving hydrogens. Figures $6 c$ and 7 were rendered using visual molecular dynamics. ${ }^{37}$

\section{Protein-Protein Docking Protocol}

In the present work, HADDOCK program was used for all the protein-protein docking studies. ${ }^{38}$ The binding site-III residues of leptin (SER 29, VAL 30, SER 31, GLN 34, LYS 35, PHE 41, SER 120, THR 121, and SER 122) and the residues in Ig-like domain of LEPR that are crucial for LEPR activation (LEU 370, ALA 407, TYR 409, HIS 417, and HIS 418) were specified in the HADDOCK input for site-specific 

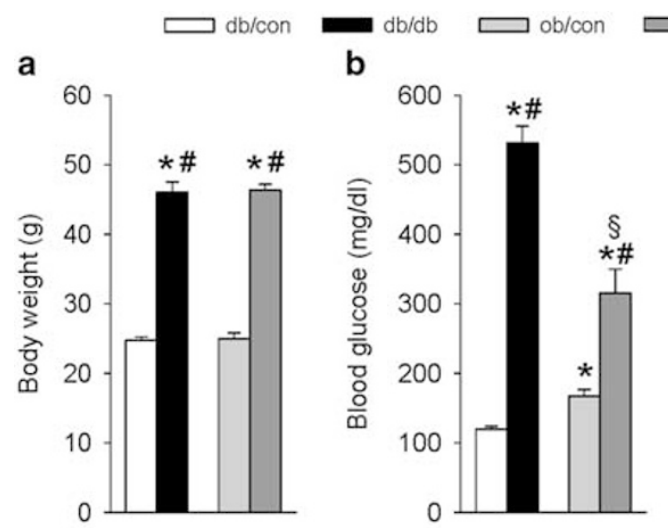

c ob/ob

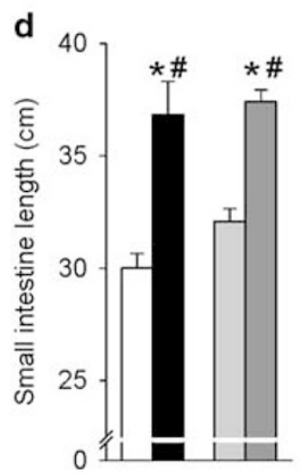

\section{e}
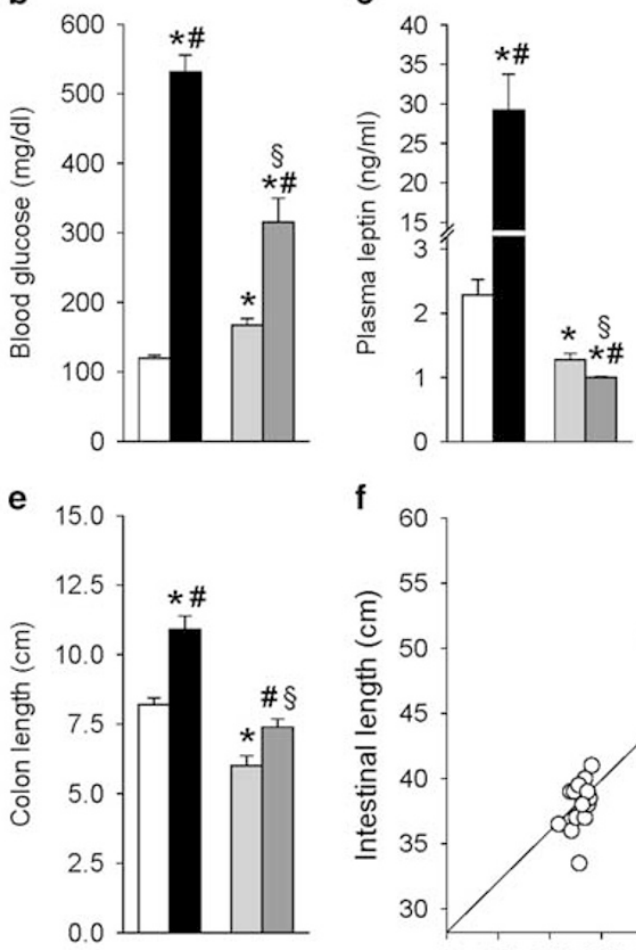

f

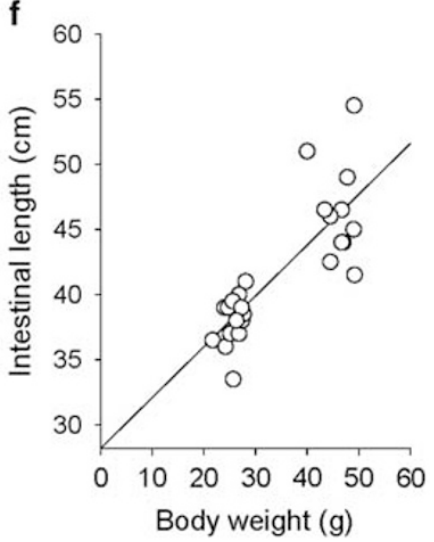

Figure 1 Hyperleptinemic and leptin-deficient mice are obese, hyperglycemic, and exhibit an increase in total intestinal length. Hyperleptinemic ( $d b / d b$ ) and leptin-deficient (ob/ob) mice, as commonly published, are both obese (a) and hyperglycemic (b). Blood glucose was significantly lower in ob/ob vs $d b / d b$ mice. Plasma leptin levels were significantly higher in $d b / d b$ mice and at the lower detection limit in ob/ob mice (c). Total small intestinal length (d) as well as colon length (e) were increased in both $d b / d b$ and ob/ob mice compared with controls (db/con and ob/con) that positively correlated (f) with body weight $\left(r^{2}=0.7\right) . N=5-10 /$ genotype. ${ }^{*} P<0.05$ vs db/con, ${ }^{\#} P<0.05$ vs ob/con, ${ }^{\S} P<0.05$ vs $d b / d b$.

docking. ${ }^{39}$ The docking of CST was kept confined around the Ig-like domain of LEPR.

\section{CST Treatment}

Mice with free access to food and water were injected with CST, a 21-amino acid fragment of chromogranin A $(5 \mathrm{mg} / \mathrm{kg}$ bw dissolved in sterile water) for 7 days as described before. ${ }^{24}$ Administration of CST at this dosage was shown to increase plasma CST levels by approximately twofold in wild-type mice. ${ }^{24}$ Body weight and blood glucose were determined. ${ }^{40}$ Plasma leptin levels were measured by using a mouse leptin ELISA (BioVendor, Asheville, NC, USA). After 7 days, mice were killed and the small intestine removed. Intestine was prepared for either western blotting or immunofluorescence as described above. In addition, OGTT was performed in $\mathrm{db} / \mathrm{con}$ mice as described above. CST $(5 \mathrm{mg} / \mathrm{kg}$ i.p.) or vehicle (sterile water, $2 \mu \mathrm{l} / \mathrm{g}$ bw) were administered $30 \mathrm{~min}$ before oral glucose loading. In the CST-treated group, CST ( $5 \mathrm{mg} / \mathrm{kg}$ ) was also added to the oral glucose solution.

\section{Statistical Analysis}

The data are expressed as mean \pm s.e.m. and analyzed using GraphPad Prism v5.0 (La Jolla, CA, USA) and SigmaPlot v11.0 (San Jose, CA, USA) software. Unpaired and paired Student's $t$-tests as well as ANOVA followed by Bonferroni post test was performed, as appropriate, to analyze for statistical differences between groups with $P<0.05$ considered statistically significant.

\section{RESULTS}

\section{Effect on Body Weight, Blood Glucose, and Intestinal Morphology}

Both hyperleptinemic and leptin-deficient mice were found to be obese $(46.1 \pm 1$ vs $26.7 \pm 2 \mathrm{~g}$ and $46.3 \pm 1$ vs $25.0 \pm 1 \mathrm{~g}$, respectively; $P<0.01)$ and hyperglycemic $(532 \pm 24$ vs $120 \pm 4 \mathrm{mg} / \mathrm{dl}$ and $315 \pm 34$ vs $168 \pm 9 \mathrm{mg} / \mathrm{dl}$, respectively; $P<0.01$ ) compared with controls (Figures $1 \mathrm{a}$ and $\mathrm{b}$ ). Both $d b /$ $d b$ and $o b / o b$ mice exhibited increased small intestinal length $(36.8 \pm 2$ vs $30.0 \pm 1 \mathrm{~cm}$ and $37.4 \pm 1$ vs $32.1 \pm 1 \mathrm{~cm}$, respectively; $P<0.01)$ as well as colon length $(10.9 \pm 0.5 \mathrm{vs}$ $8.2 \pm 0.3 \mathrm{~cm}$ and $7.4 \pm 0.3$ vs $6.0 \pm 0.4 \mathrm{~cm} ; P<0.05)$ compared 

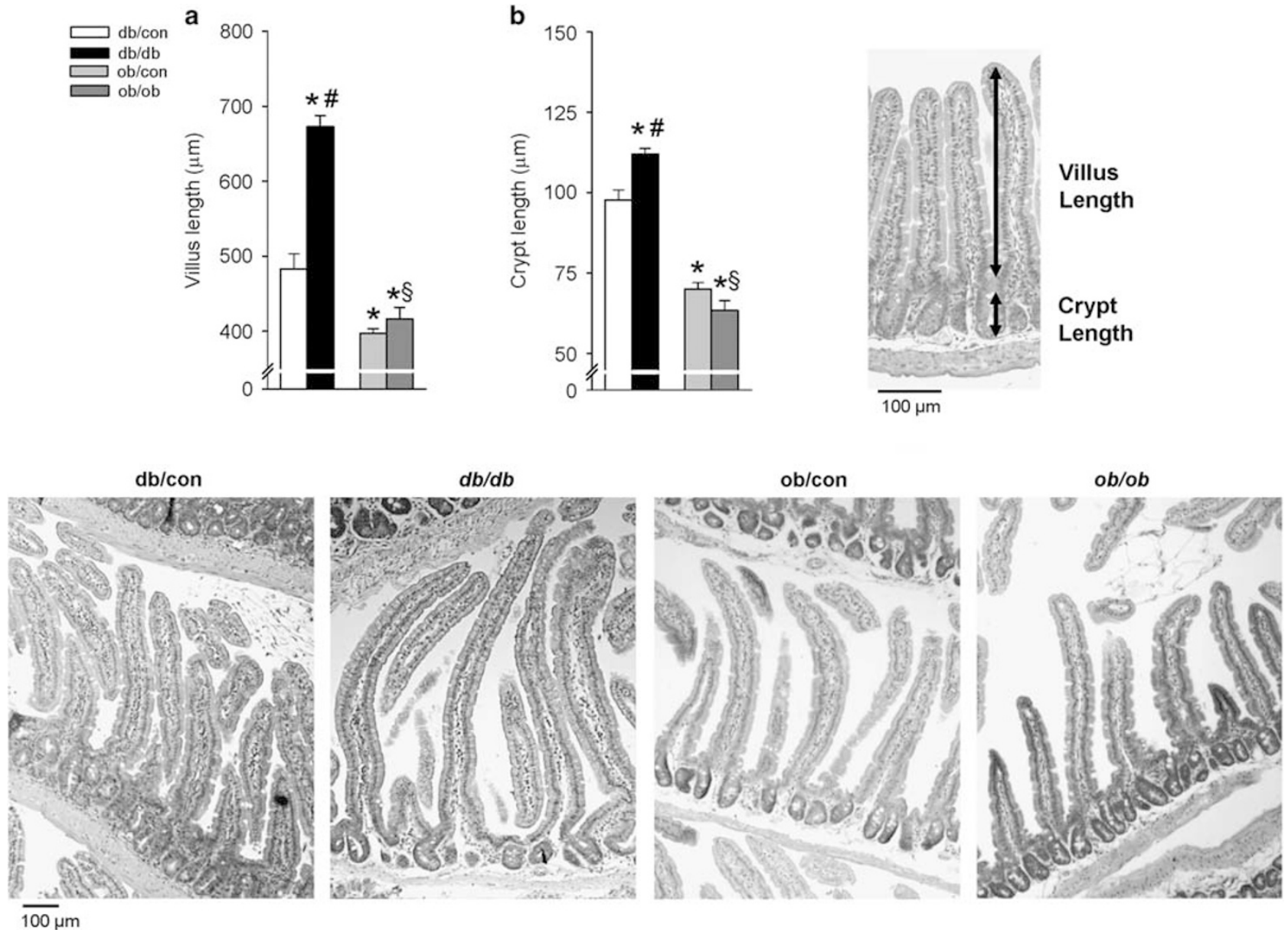

Figure 2 Intestinal hyperplasia is leptin dependent. Hyperleptinemic $(d b / d b)$ mice exhibit longer villi (a) and deeper crypts (b) compared with their controls ( $d b / c o n)$. However, leptin-deficient $(o b / o b)$ mice and their controls (ob/con) had similar villi and crypt lengths (a and b). Representative images are shown. $N=4-5 /$ genotype. ${ }^{*} P<0.05$ vs db/con, ${ }^{\#} P<0.05$ vs ob/con, ${ }^{\S} P<0.05$ vs $d b / d b$.

with controls (Figures 1d and e). Our data further show that there is a correlation between body weight and intestinal length (Figure 1f) that is independent of leptin levels (Figure 1c). Interestingly, only hyperleptinemic $d b / d b$ mice exhibited an increase in mucosal mass. Morphometric analysis of H\&E-stained sections (Figures 2a and b) showed that $d b / d b$ mice had significantly longer villi $(673 \pm 14 v s$ $483 \pm 20 \mu \mathrm{m} ; \quad P<0.01)$ and deeper crypts $(112 \pm 2 v s$ $98 \pm 3 \mu \mathrm{m} ; P<0.01)$ compared with controls. In contrast, ob/ob mice had comparable villus lengths $(416 \pm 15$ vs $397 \pm 6 \mu \mathrm{m} ; P=$ not significant (NS)) and crypt depths $(63.3 \pm 3$ vs $70.0 \pm 2 \mu \mathrm{m} ; P=\mathrm{NS})$ compared with controls.

\section{Intestinal Proliferation and Apoptosis Is Altered in $d b / d b$ Mice}

In order to further understand the increased mucosal mass observed in hyperleptinemic mice, we quantified intestinal proliferation and apoptosis in the jejunum (Figure 3). Compared with controls, $d b / d b$ mice had a significantly increased proliferative response as determined by quantifying the number of PCNA-positive cells in the crypt compartment. Cleaved caspase- 3 staining, a specific marker for apoptosis, showed reduced apoptosis in crypts and villi tips of $d b / d b$ mice. These changes were absent in the jejunum of $o b / o b$ mice. In addition, intestinal epithelial apoptosis was quantified morphologically in H\&E-stained sections (Supplementary Figure S1). This morphological analysis confirmed the significantly decreased apoptosis in crypts of $d b / d b$ mice as compared with $\mathrm{db} / \mathrm{con}, \mathrm{ob} / \mathrm{con}$, and ob/ob mice. Taken together, these data suggest that high circulating leptin levels in $d b / d b$ mice may affect intestinal architecture.

\section{Intestinal SGLT1 Membrane Abundance Is Decreased in $d b / d b$ Mice}

As intestinal hyperplasia was present in both hyperleptinemic and leptin-deficient mice, we investigated whether the hyperglycemia seen in these mice is associated with altered expression of SGLT1 and whether there was a dependency on 
a

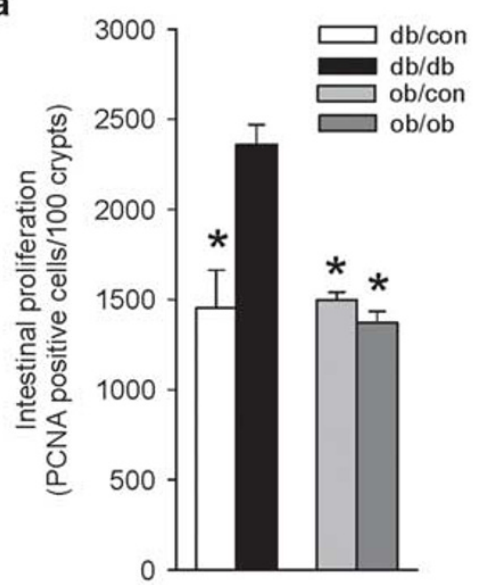

$\mathrm{db} / \mathrm{con}$

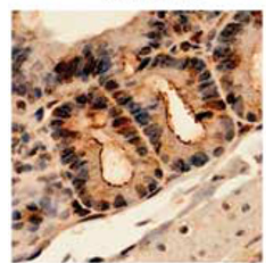

ob/con

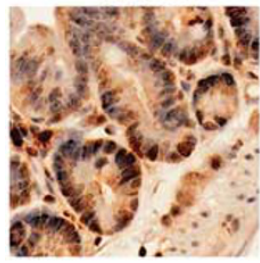

$d b / d b$

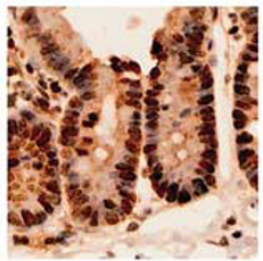

ob/ob

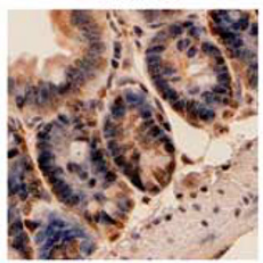

b
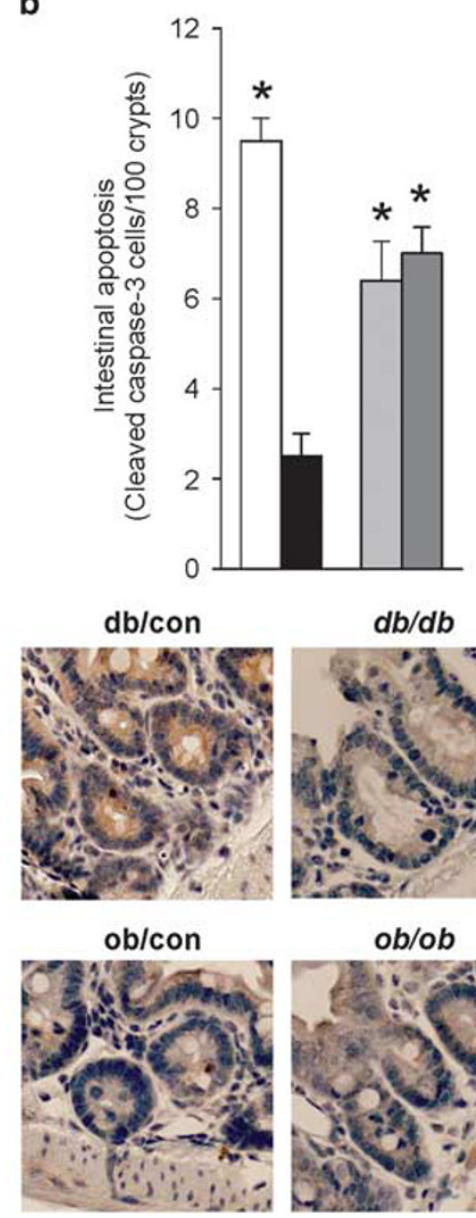

$d b / d b$

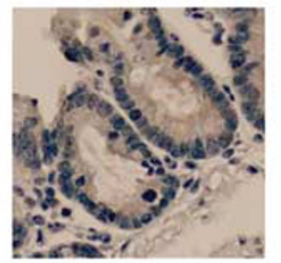

ob/ob

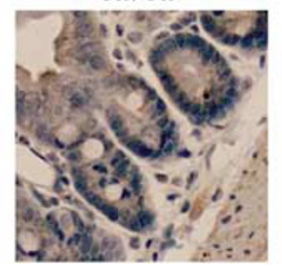

c
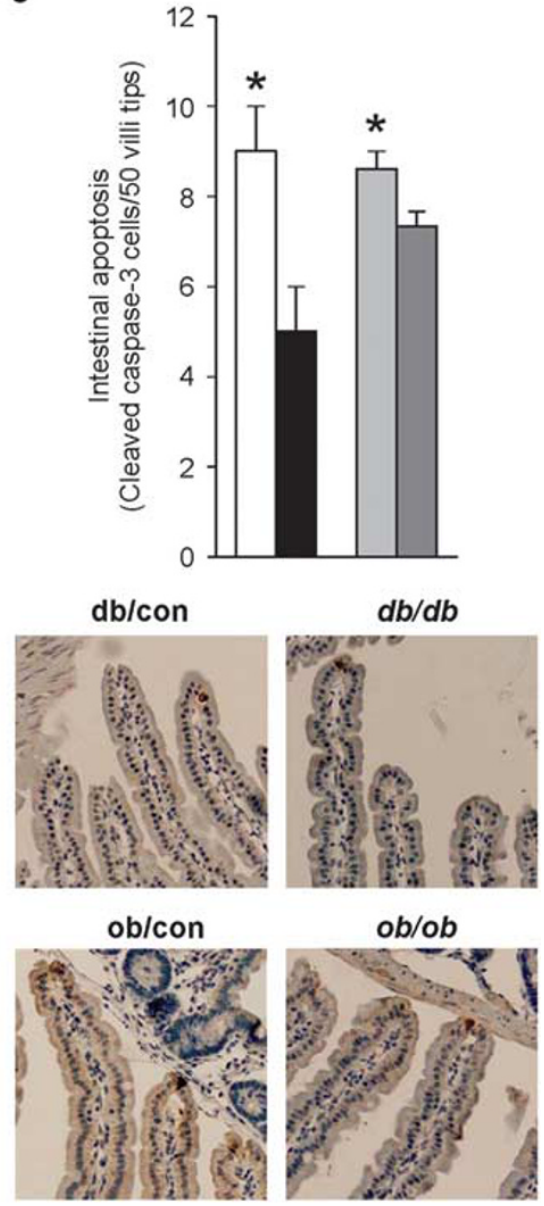

Figure 3 Intestinal hyperplasia is a consequence of enhanced proliferation and reduced apoptosis. Hyperplasia in hyperleptinemic ( $d b / d b$ ) mice is a result of an enhanced proliferative response (a, proliferating cell nuclear antigen staining), decreased epithelial apoptosis in the crypt compartment (b, cleaved caspase-3 staining), and tip of villi (c, cleaved caspase-3 staining). Proliferation and apoptosis are not different between control (ob/con) and leptin-deficient $(o b / o b)$ mice. Representative images are shown. $N=4-5 /$ genotype. ${ }^{*} P<0.05 \mathrm{vs} d b / d b$.

leptin. In this study we confirmed the specificity of the SGLT1 antibody in Sglt1 ${ }^{-1-}$ mice that lack the $\sim 76 \mathrm{kDa}$ band representing SGLT1 (Figure 4a). In hyperleptinemic $d b / d b$ mice, western blot analysis showed that intestinal SGLT1 membrane expression was $\sim 50 \%$ lower compared with control mice (Figures 4a and b). Qualitative immunofluorescence confirmed a markedly reduced abundance of SGLT1 on the apical membrane of enterocytes, but an increase in cytoplasmic staining in $d b / d b$ mice (Figure $4 c)$. In contrast, immunofluorescence of SGLT1 in leptin-deficient $o b / o b$ mice revealed no differences compared with controls (Figure 4c). These data suggest that leptin can determine intestinal SGLT1 membrane expression; however, this effect seems independent of the long form of the leptin receptor, LEPRb. To determine whether the small intestinal brush border membranes of $d b / d b$ and Sglt ${ }^{-1-}$ mice express apical markers indicative of normally differentiated enterocytes, we analyzed the distribution of intestinal alkaline phosphatase, an enzyme that is targeted exclusively to the apical brush border membrane. Alkaline phosphatase staining in $d b / d b$ mice, which have significantly reduced intestinal SGLT1 abundance, as well as in Sglt1 ${ }^{-1-}$ mice did not reveal any difference compared with animals with intact (db/con, ob/con, or $o b / o b)$ intestinal SGLT1 abundance (Figure 5). To study whether there is a functional relevance caused by the increased leptin levels that possibly reduce intestinal SGLT1 abundance, we performed OGTT in control and $d b / d b$ mice in the presence and absence of phlorizin, a SGLT1/2 inhibitor. Phlorizin significantly improved glycemic control and reduced the AUC in control mice compared with glucose alone (Figures 6a and b). In contrast, $d b / d b$ mice showed an OGTT and AUC that were not significantly different from control mice treated with phlorizin; in addition, phlorizin treatment mimicked the phenotype of Sglt1 ${ }^{-1-}$ mice (Figures $6 \mathrm{a}$ and b) that completely lack $\mathrm{Na}^{+}$-dependent glucose transport in the intestine. $^{3}$ 
a

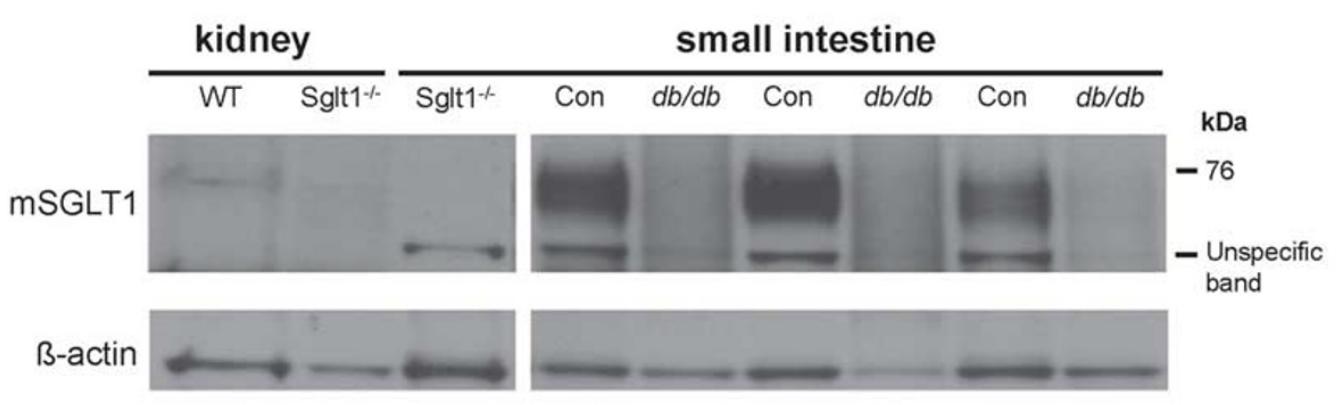

C

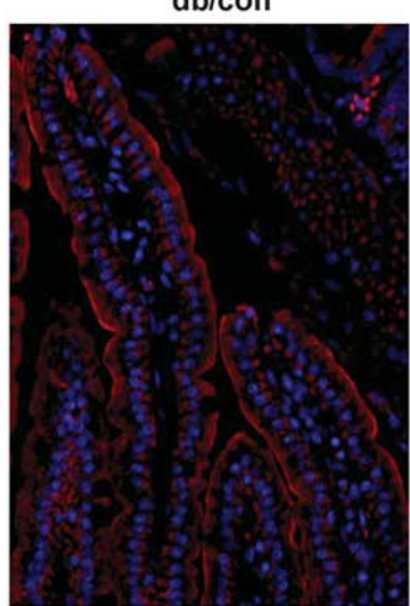

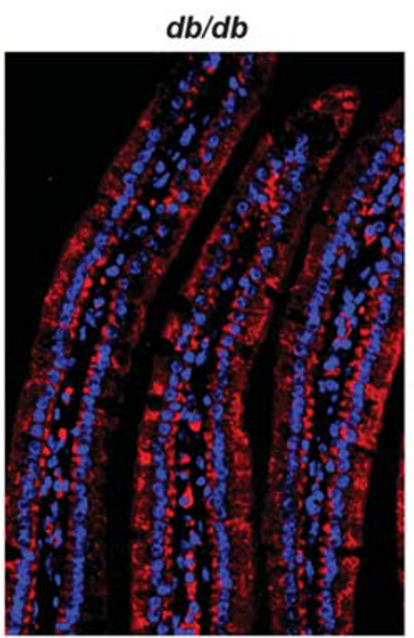

ob/con

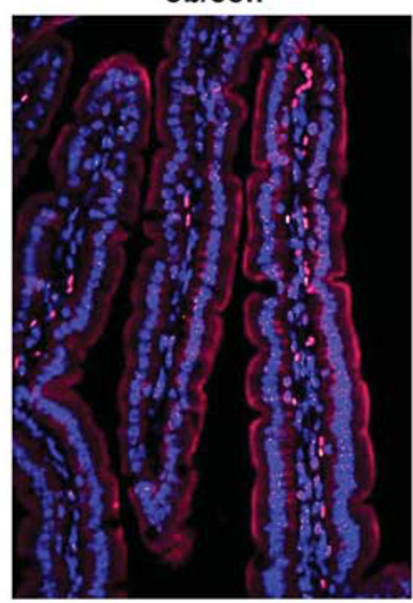

b

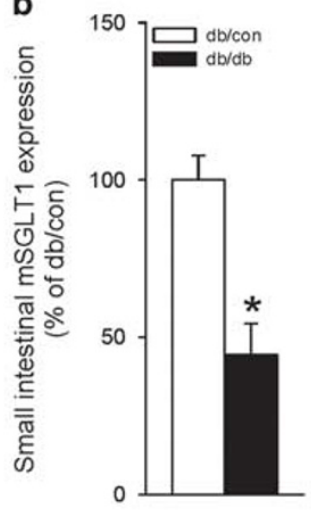

ob/ob

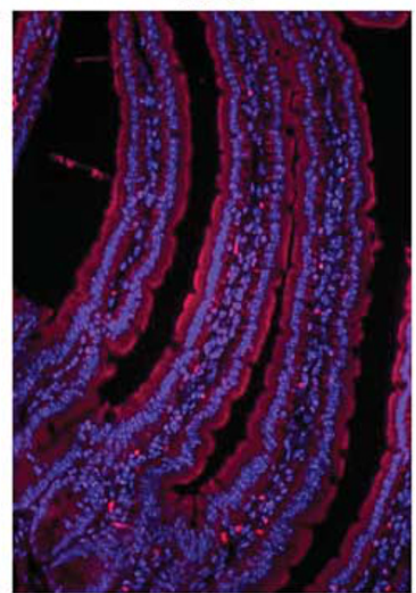

Figure 4 Intestinal SGLT1 expression is decreased in hyperleptinemic mice but not leptin-deficient mice. Hyperleptinemic ( $d b / d b)$ mice exhibit a significant decrease in membrane protein expression ( $\mathbf{a}$ and $\mathbf{b}$ ) and apical membrane abundance (c) of intestinal SGLT1. In contrast, SGLT1 membrane abundance (c) in leptin-deficient (ob/ob) mice was not different than their controls (ob/con). Tissue from a SGLT1 knockout mouse (Sglt1 ${ }^{-1-}$ ) was used as a control to verify antibody specificity (a). $N=4-5 /$ genotype. ${ }^{*} P<0.05 \mathrm{vs} \mathrm{db} / \mathrm{con}$.

\section{Leptin AB-loop and CST Are Structurally Similar}

The pairwise sequence alignment between CST and the AB-loop of leptin indicates a $>40 \%$ sequence similarity (Figure 7a). A high sequence and structural similarity is indicative of CST potentiality to bind to the LEPR. The secondary structure prediction program, PSIPRED, predicted a high propensity of $\beta$-strands and random coils in the structures of both CST and the missing AB-loop region of leptin (Figure $7 \mathrm{~b}){ }^{41}$ Results from the MD simulations also suggested the existence of $\beta$-strands in both structures that eventually form a stable $\beta$-sheet during the time evolution of MD simulations. The time-averaged structures of CST and leptin with the missing AB-loop are shown in Figure $7 \mathrm{c}$.

\section{Leptin and CST Exhibit a Common Binding Site in the LEPR}

From the sequence and structural analysis of leptin and CST, it was evident that CST mimics leptin's binding site-III, particularly the AB-loop. As mutagenesis results revealed that the binding site-III of leptin binds to the Ig-like domain of
LEPR, both leptin and CST docking were targeted to the Ig-like domain of LEPR. Both ligands exhibit very similar modes of binding to the receptor, as shown in Figure 8 . Table 1 lists all the interacting residues, including the common ones in LEPR that interact with both CST and leptin. Notably, conserved cluster of Ig-like domain residues that are crucial for LEPR activation, LEU 372, HIS 419, and HIS 420, were found to be involved in interactions with leptin and CST. Apart from these interactions, leptin and CST have common interactions with TRP 369, ASN 371, ALA 373, GLU 374, LYS 375, CYS 412, ASN 414, HIS 416, GLU 417, CYS 418, ARG 421, and TYR 422 residues in the Ig-like domain of LEPR. The above results suggest that CST could compete with leptin for binding to LEPR and might exhibit partial leptin-like agonist activity. We think that in leptin-deficient conditions, CST possibly mimics binding site-III of leptin to bind to the Ig-like domain of LEPR and might elicit leptin-like activity for LEPR signaling. Vice versa, under conditions where leptin is drastically elevated, as found in hyperleptinemic $d b / d b$ mice, CST may block the action of the full agonist, leptin. 

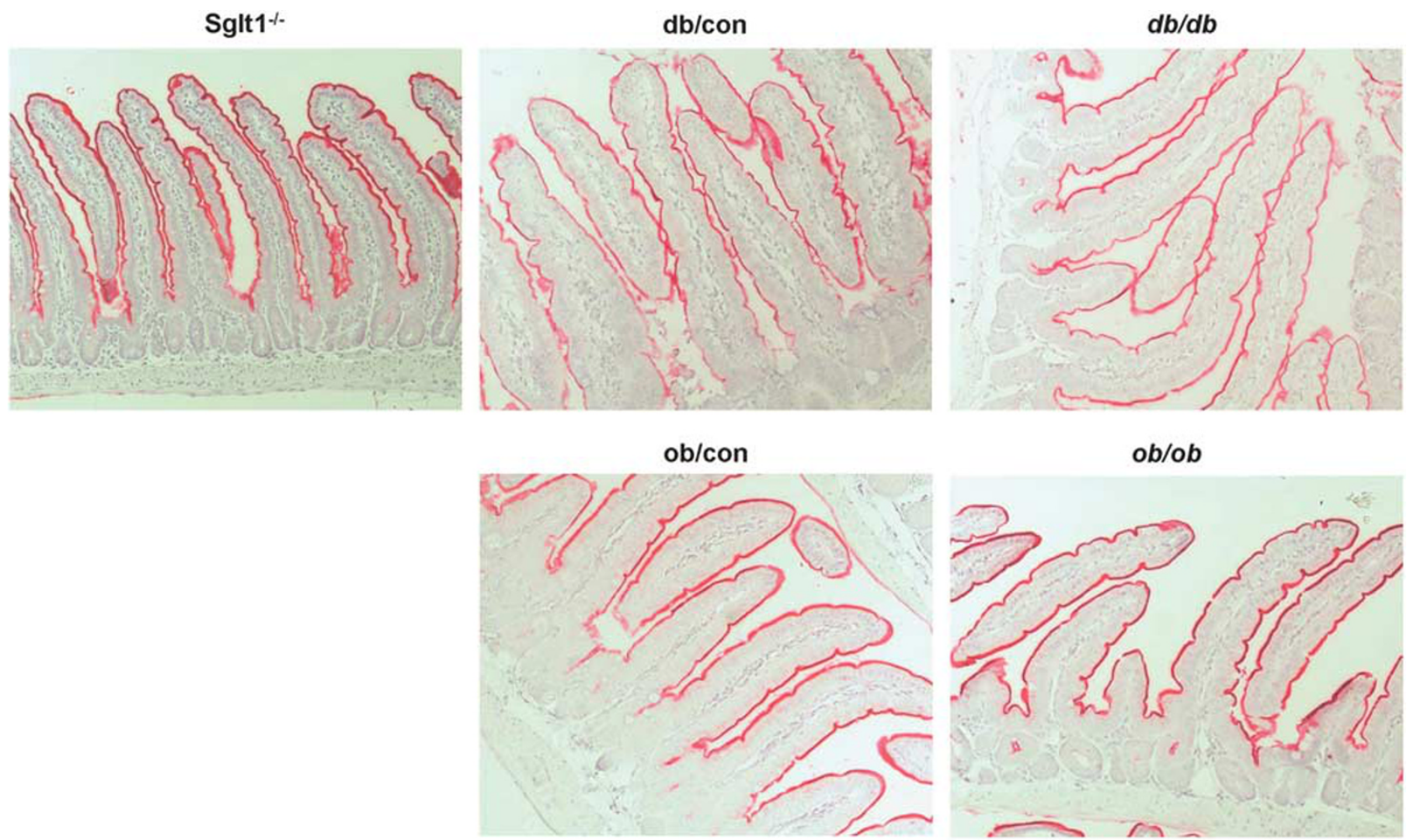

Figure 5 Terminal differentiation in enterocytes in unaffected by leptin levels or lack of SGLT1. Enterocytes were assessed by staining sections of small intestines of SGLT1 knockout mice (Sglt $1^{-/}$), hyperleptinemic $d b / d b$ mice and their controls ( $\mathrm{db} / \mathrm{con}$ ), as well as leptin-deficient (ob/ob) mice and their control mice (ob/con) for intestinal alkaline phosphatase. No differences were observed in the staining patter of this absorptive cell lineage marker between genotypes, indicating comparable terminal differentiation of enterocytes in all genotypes.

\section{CST Treatment Restored Villus Length, Intestinal Proliferation, and SGLT1 Abundance in $d b / d b$ Mice}

As we found that LEPRb is not necessary or sufficient for the decreased membrane abundance of SGLT1 in hyperleptinemic $d b / d b$ mice, and CST might affect LEPR signaling, we studied the role of CST in hyperleptinemic $d b / d b$ mice on intestinal morphology and SGLT1 abundance. In a separate cohort, $d b / d b$ and control mice were treated with CST (Figure 9). After 7 days, blood glucose levels rose higher in $d b / d b$ than in control mice $(232 \pm 51$ vs $50 \pm 12 \Delta \mathrm{mg} / \mathrm{dl}$; $P<0.05)$ that corresponded to normalized villus length and proliferation as well as restored SGLT1 protein expression and membrane abundance to levels seen in controls (for representative PCNA staining see Supplementary Figure S2). The short-term CST treatment was without effect on body weight or changes in leptin levels (Figure 9). To determine whether there is an ambient contribution of leptin and a possible interaction with CST for intestinal glucose uptake, we performed OGTT in the presence and absence of CST in control mice. Pretreament with CST (30 min before oral glucose loading) did not affect blood glucose levels measured immediately before glucose loading (Supplementary Figure S3). The OGTT and AUC were not different between CST-treated and vehicle-treated control mice.

\section{DISCUSSION}

By studying the role of leptin and its receptors in hyperleptinemic and leptin-deficient obese diabetic mice, we provide evidence that leptin signaling plays a central role in intestinal homeostasis. The present studies show for the first time that leptin-induced downregulation of intestinal SGLT1 is possibly mediated by the short form of the leptin receptor, LEPRa. This may prevent overt hyperglycemia under diabetic conditions where hyperleptinemia is present. In addition, our modeling analyses indicate that CST may compete with leptin for binding to LEPR; thus, CST might contribute to the regulation of energy homeostasis and epithelial turnover.

The proximal small intestine is the major site for nutrient absorption; however, little is known about the role of the intestine in models of obesity and diabetes. Intestinal and renal hyperplasia and hypertrophy, respectively, are features that have been described in type 2 diabetic patients. ${ }^{42-44}$ In theory, an increased absorptive surface area with more transporters available for nutrient absorption could contribute, at least in part, to the development of obesity in these mice. However, our findings and those of others provide evidence that an increase in mucosal mass does not always correlate with obesity. We found that obese $d b / d b$ mice, which have deficient LEPRb, exhibited an increase in mucosal mass with longer villi and deeper crypts compared with their 
a

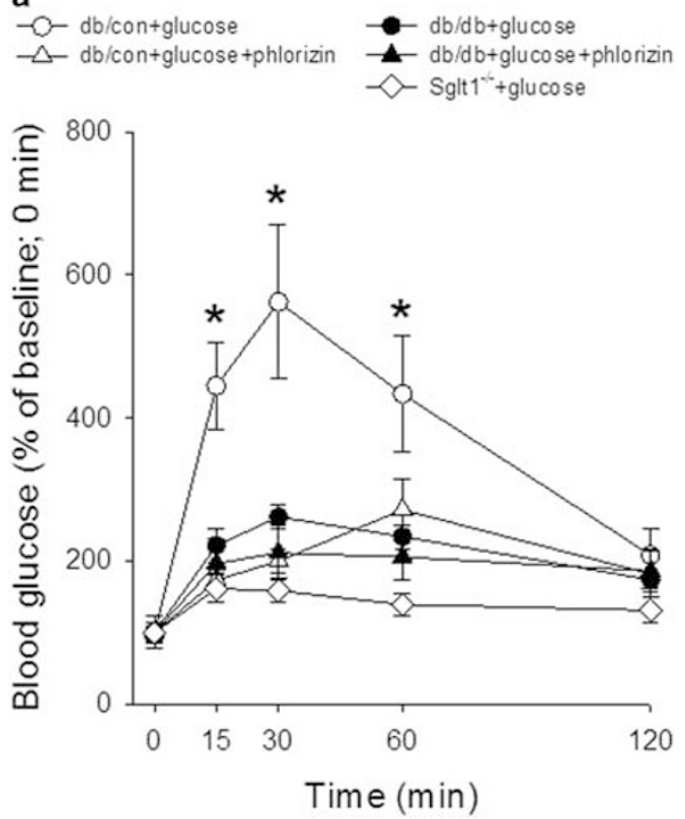

b

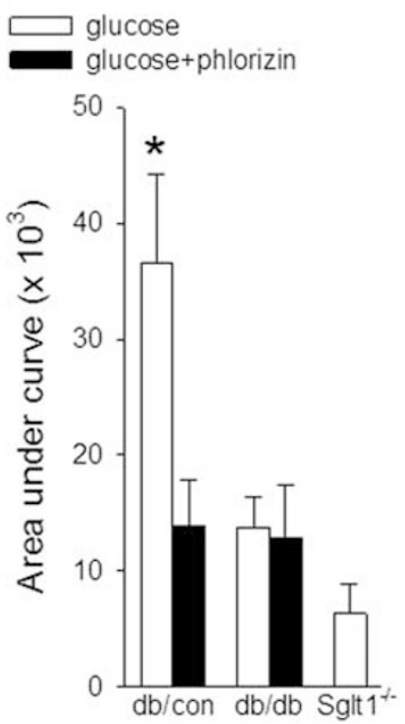

Figure 6 Phlorizin (SGLT1/2 inhibitor) significantly improves glycemic status in control mice (db/con) but is without effect in hyperleptinemic ( $d b / d b)$ mice. Oral glucose tolerance test (OGTT) was performed (glucose $2 \mathrm{~g} / \mathrm{kg}, 1 \%$ of bw via oral gavage) with or without phlorizin (0.5 g/kg) after overnight fasting. Phlorizin significantly reduced blood glucose (a) and area under the curve (b) in db/con mice. In contrast, OGTT and area under curve were not different between glucose-treated $d b / d b$ mice compared with glucose+phlorizin-treated $d b / d b$ or $\mathrm{db} / \mathrm{con}$ mice. For comparison, SGLT1 knockout mice $\left(S g l t 1^{-/}\right)$that completely lack $\mathrm{Na}^{+}$-dependent glucose uptake in the small intestine are shown. $N=4-8 /$ genotype. ${ }^{*} P<0.05$ vs db/con glucose.

lean controls. In contrast, we did not find an increase in mucosal mass in obese leptin-deficient $o b / o b$ mice. Furthermore, mucosal mass is increased when rats are administered exogenous leptin, ${ }^{45}$ and intestinal epithelial cell-specific LEPRb knockout mice also display increased mucosal mass but have normal body weights compared with wild-type mice. ${ }^{46} \mathrm{We}$ also found that there was a positive correlation between intestinal length and body weight; indeed, both hyperleptinemic and leptin-deficient mice had much longer small intestine and colon lengths than their lean controls. A similar correlation was found in humans where the length of the small intestine, colon, and whole intestine increased with body weight. ${ }^{47}$ The fact that both hyperleptinemic $d b / d b$ and leptin-deficient $o b / o b$ mice have longer intestines, but only $d b / d b$ mice display an increase in mucosal mass, indicates that the overall growth in total length is a factor of body mass whereas mucosal hyperplasia is leptin dependent.

Does defective signaling through LEPRb have an effect on intestinal epithelial cell turnover that potentially could lead to the increase in mucosal mass observed in $d b / d b$ mice? We found that $d b / d b$ mice exhibited increased intestinal epithelial proliferation and decreased apoptosis in the crypts of the small intestine. As the crypts house stem cells and proliferating daughter cells, the combination of increased proliferation (PCNA) and decreased apoptosis in crypts and tips of villi (cleaved caspase-3 and $\mathrm{H} \& \mathrm{E}$ ) enhance renewal of the crypt-villus structure, leading to mucosal hyperplasia. We did not find an increase in mucosal mass in leptin-deficient $o b / o b$ mice. Along those lines, ob/ob mice exhibited decreased cellular proliferation and increased apoptosis in intestinal epithelial cells after massive small bowel resection. ${ }^{48}$ The fact that we did not find an increase in mucosal mass in leptin-deficient mice implies that leptin signaling through a leptin receptor other than LEPRb is mediating this effect in $d b / d b$ mice. Of note, previous data on the expression of LEPRb in the intestine are conflicting, with studies reporting absent LEPRb mRNA expression in the intestine, ${ }^{12}$ an approximately eightfold higher LEPRa vs LEPRb mRNA expression, ${ }^{18}$ or the presence of LEPRb protein and/or mRNA without comparison with other LEPRs. ${ }^{46,49}$ A comparable situation regarding differences of leptin receptor isoform expression was described in pulmonary responses to leptin. ${ }^{50}$ Further studies are needed to better understand the role of these receptors in the intestinal proliferative response.

Studies have shown that leptin signaling can regulate expression of nutrient transporters in the intestine, ${ }^{46,51-53}$ and it was demonstrated that mucosal leptin enhanced insertion of GLUT2/5 and reduced insertion of SGLT1 on the apical membrane of enterocytes. ${ }^{51}$ Our study is the first one that localized SGLT1 in the intestine of $d b / d b$ and $o b / o b$ mice with an antibody verified to have no signal in Sglt $1^{-/-}$mice. We provide evidence that in the absence of leptin (ob/ob mice), SGLT1 abundance is unaffected indicating that leptin itself is not a prerequisite for a tonic or homeostatic regulation of SGLT1 expression, whereas in the absence of LEPRb, which causes the mice to be severely hyperleptinemic, SGLT1 
a

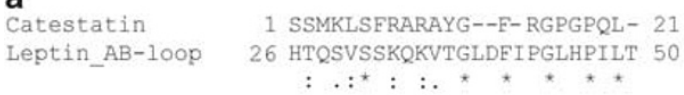

b

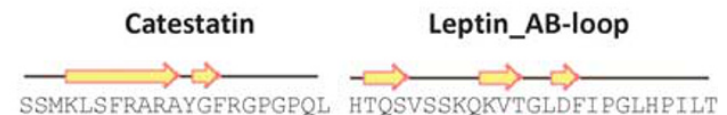

c
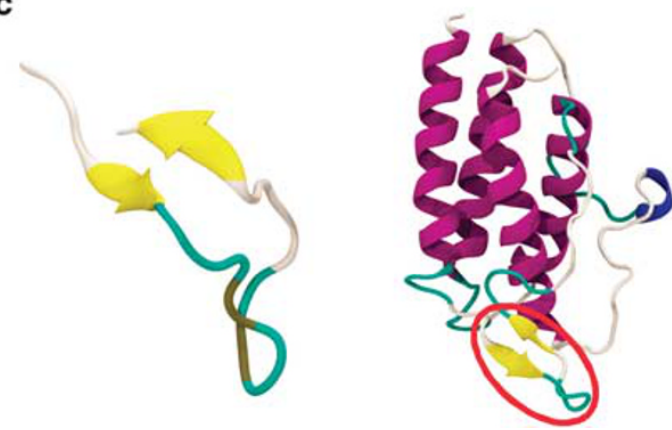

Figure $7 \mathrm{~A}$ high sequence and structural similarity between CST and leptin AB-loop is indicative of CST potentiality to bind to LEPR. (a) The pairwise sequence alignment between CST and the AB-loop of leptin binding site-III show $>40 \%$ similarity. In the alignment, ${ }^{\prime * \prime}$ indicates positions with identical amino acid residues, ' $:$ ' indicates positions of residues with very similar nature, and '. indicates positions of residues with similar nature in the sequence. (b) Secondary structure prediction method identifies high propensity of $\beta$-strands and random coils in the structures of CST and leptin's AB-loop. (c) Time-averaged structures of CST and leptin, as obtained from MD simulations. Interestingly, CST resembles the 'thumb-like' domain of leptin's AB-loop (highlighted in red) that was distorted in the crystal structure and remains undefined structurally, possibly relating to the high flexibility of the region.

abundance is significantly reduced. It is possible that reduced expression of intestinal SGLT1 in $d b / d b$ mice might be a consequence of mislocalization or a general defect of brush border membrane protein expression. Our experiments studying localization of intestinal alkaline phosphatase argue against such a phenomenon because we were able to detect terminally differentiated enterocytes in all studied genotypes. Consistent with our findings, increased intestinal epithelial proliferation in $d b / d b$ mice is not the consequence of abnormal gut development because at day E18.5 $d b / d b$ and $d b / c o n$ mice show no difference in intestinal and villi length or gross intestinal morphology. ${ }^{54}$

Evidence for the involvement of leptin in such regulation comes from studies where glucose transport, as well as SGLT1 expression, was studied in genetically obese $f a / f a$ rats. This study showed that luminal leptin can acutely inhibit $\mathrm{Na}^{+}$-dependent glucose transport and reduced brush border membrane SGLT1 protein levels. ${ }^{52}$ Intestinal-specific deletion of LEPRb resulted in downregulation of SGLT1 and delayed onset of obesity. ${ }^{46}$ However, the mechanism of other leptin receptors was not determined. To our knowledge, only one study determined jejunal SGLT1 protein in $o b / o b$ mice that, supporting our findings, showed comparable SGLT1 protein

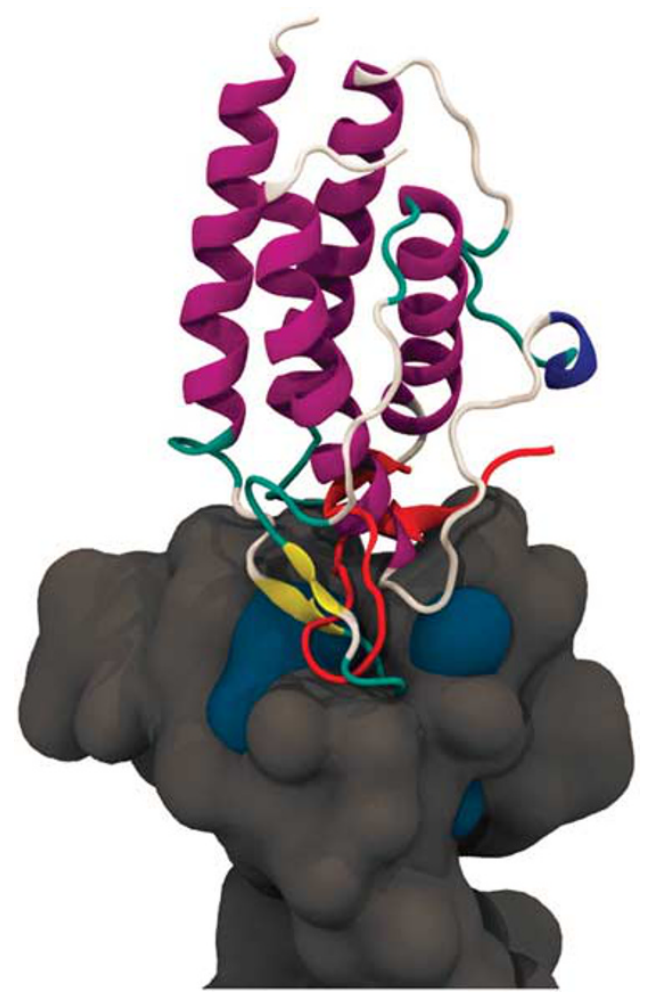

Figure 8 Binding model of CST and leptin to LEPR is very similar. Protein-protein docking was performed with the MD simulation generated time-averaged structures of CST, leptin, and LEPR. Independent docking of leptin binding site-III and CST was performed targeting the Ig-like domain of LEPR, as suggested by the recent mutagenesis studies. The best-docked (energetically) complex from each category was superimposed onto each other to compare their mode of interaction with LEPR. The Ig-like domain of LEPR is represented by gray surface with its residues that are known to be critical for LEPR activation and leptin binding is highlighted in blue. CST is shown in red and leptin $a$-helices, $\beta$-strands, and random coils are shown in purple, yellow, and white/cyan, respectively.

expression to lean mice. ${ }^{55}$ As leptin levels were comparable between wild-type and intestine-specific LEPRb knockout mice, and yet they still observed diminished SGLT1 expression, ${ }^{46}$ it is important to determine whether this is a direct effect of LEPRb on SGLT1 or whether administration of exogenous leptin could even further reduce intestinal SGLT1 abundance.

A recent study suggested that CST regulates energy homeostasis via the leptin receptor. ${ }^{24}$ By using modeling approaches, we identified that the AB-loop of leptin and CST have a high structural similarity. The AB-loop of leptin is of particular interest as it was recently described that mutations in the 39-42 amino acid fragment of the AB-loop act as competitive LEPR antagonists. ${ }^{56}$ All double-, triple-, and quadruple-mutated muteins tested for residues 39-42 were found to act as true antagonists, that is, they interacted with the LEPR with an affinity similar to wild-type leptin while not showing any biological activity. ${ }^{56}$ Of note, the same region 
Table 1 Interacting residues of leptin binding site-III and CST with Ig-like domain of leptin receptor

\begin{tabular}{|c|c|c|c|}
\hline LEPR & Leptin & LEPR & CST \\
\hline SER 363 & SER 25 & ILE 334 & SER 2 \\
\hline LYS 364 & HIS 26 & TRP 369* & MET 3 \\
\hline GLU 365 & GLN 28 & ASN $371^{*}$ & LYS 4 \\
\hline TRP 369* & SER 29 & $\underline{\text { LEU } 372^{*}}$ & LEU 5 \\
\hline ASN $371^{*}$ & VAL 30 & ALA $373^{*}$ & SER 6 \\
\hline$\underline{\text { LEU } 372^{*}}$ & SER 31 & GLU 374* & PHE 7 \\
\hline ALA 373* & SER 32 & LYS $375^{*}$ & ARG 8 \\
\hline GLU $374^{*}$ & LYS 33 & GLN 378 & ALA 9 \\
\hline LYS 375* & GLN 34 & CYS 412* & ARG 10 \\
\hline TYR 411 & MET 68 & ASN 414* & ALA 11 \\
\hline CYS $412^{*}$ & PRO 69 & GLU 415 & TYR 12 \\
\hline ASN 414* & SER 70 & HIS 416* & GLN 20 \\
\hline HIS 416* & ARG 71 & GLU $417^{*}$ & LEU 21 \\
\hline GLU $417^{*}$ & ASN 72 & CYS 418* & \\
\hline CYS $418^{*}$ & GLY 118 & HIS 419* & \\
\hline HIS 419* & TYR 119 & $\underline{\text { HIS } 420^{*}}$ & \\
\hline HIS 420* & SER 120 & ARG $421^{*}$ & \\
\hline ARG $421^{*}$ & THR 121 & TYR 422* & \\
\hline \multirow[t]{2}{*}{ TYR 422* } & GLU 122 & & \\
\hline & VAL 123 & & \\
\hline
\end{tabular}

The residues that are in bold and underlined are important for receptor activation. Common LEPR interacting residues in both protein-protein complexes are labeled by ${ }^{\prime *}$.

was found to be required for di- or tetra-merization, and therefore LEPR activation because this effect is absent when the binding site-III functionality is abolished. Mutations of other amino acid residues in the AB-loop including S29Q/V30Q/S31N and Q34S/R35S also result in impaired leptin signaling. ${ }^{33}$ Although the exact effect of the CST-leptin interaction on intracellular signaling events still needs to be determined in future studies, it seems possible that CST could bind to the LEPR and modulate its biological activity.

As hyperleptinemic $d b / d b$ mice have fully functional LEPRa, but lack functional LEPRb, we hypothesized that treatment with CST would compete with leptin for binding to LEPRa and decrease leptin action. This prompted us to assess the role of LEPRa signaling for SGLT1 regulation. We found that after 7 days of CST treatment, intestinal SGLT1 expression and abundance in $d b / d b$ mice was completely restored. However, this restoration was associated with an increase in blood glucose in $d b / d b$ and control mice that we think is possibly mediated by LEPRa. Interfering with LEPR signaling via CST under supraphysiological leptin levels (as found in $d b / d b$ mice) restores SGLT1 abundance and consequently increases blood glucose levels. Of note, CST treatment normalized intestinal proliferation and villus length. Although there is a long-term effect of CST on intestinal SGLT1 abundance, proliferation, villus length, and blood glucose levels, this study did not show an acute effect of CST on intestinal glucose uptake in OGTT. This discrepancy may be because of the time frame of the experiments and/or gastric breakdown of the CST peptide (when added to the glucose gavage solution as done in our experiments). Further studies are needed to better understand the interaction of CST and leptin as well as identify the possible existence of other factors involved in regulating intestinal turnover and $\mathrm{Na}^{+}$-dependent glucose transport, the latter possibly ex vivo by employing Ussing chambers experiments.

Recent data suggest that CST can improve leptin signaling in chromogranin A knockout mice that are found to be hyperleptinemic. $^{24}$ Consistent with our hypothesis, CST treatment in a diet-induced obesity mouse model, which results in peripheral resistance to leptin, ${ }^{57}$ was able to increase lipolysis and decrease body weight and adipose tissue mass. ${ }^{24}$ At this point we only can postulate reasons for these responses: (1) chromogranin A knockout mice have only mildly elevated plasma leptin levels that might pose a less stringent stressor compared with the severely elevated plasma leptin levels observed in $d b / d b$ mice, (2) in contrast to the preserved leptin signaling in the brain of diet-induced obesity mouse models, LEPRb-mediated signaling is absent in the entire body of $d b / d b$ mice that might contribute to different responses, and (3) in ob/ob mice where CST does not directly influence leptin receptor signaling, other regulatory factors might contribute to these contrasting responses. Of note, CST possibly has opposing effects on leptin signaling in different organs that may be based on LEPR isoform expression. The use of tissue-specific LEPR isoform knockout models and diet-induced obesity models might help determine the reason for these differences.

Although this study provides insights into the role of leptin for intestinal hyperplasia and SGLT1 abundance, it has a number of limitations. Our results show for the first time that leptin signaling, possibly through LEPRa, mediates the downregulation of SGLT1 protein and localization. However, we are yet to determine whether hyperplasia and/or SGLT1 abundance is directly regulated via LEPRa because other short forms of the leptin receptor, including LEPRc, d, and f, are also functional. The complexity of the system is reinforced by the existence of heteromerization between different LEPR isoforms. ${ }^{58,59}$ In addition, there is a possibility that hyperplasia and/or SGLT1 abundance in the intestinal mucosa are indirectly regulated via signaling of a different pathway/hormone.

In summary, we are just beginning to understand the role of different LEPR isoforms for intestinal homeostasis and glucose transport. The current results demonstrate that leptin regulates intestinal proliferation, apoptosis, and SGLT1 abundance. Hyperleptinemic obese type 2 diabetic mice have severely reduced intestinal SGLT1 membrane abundance. In 

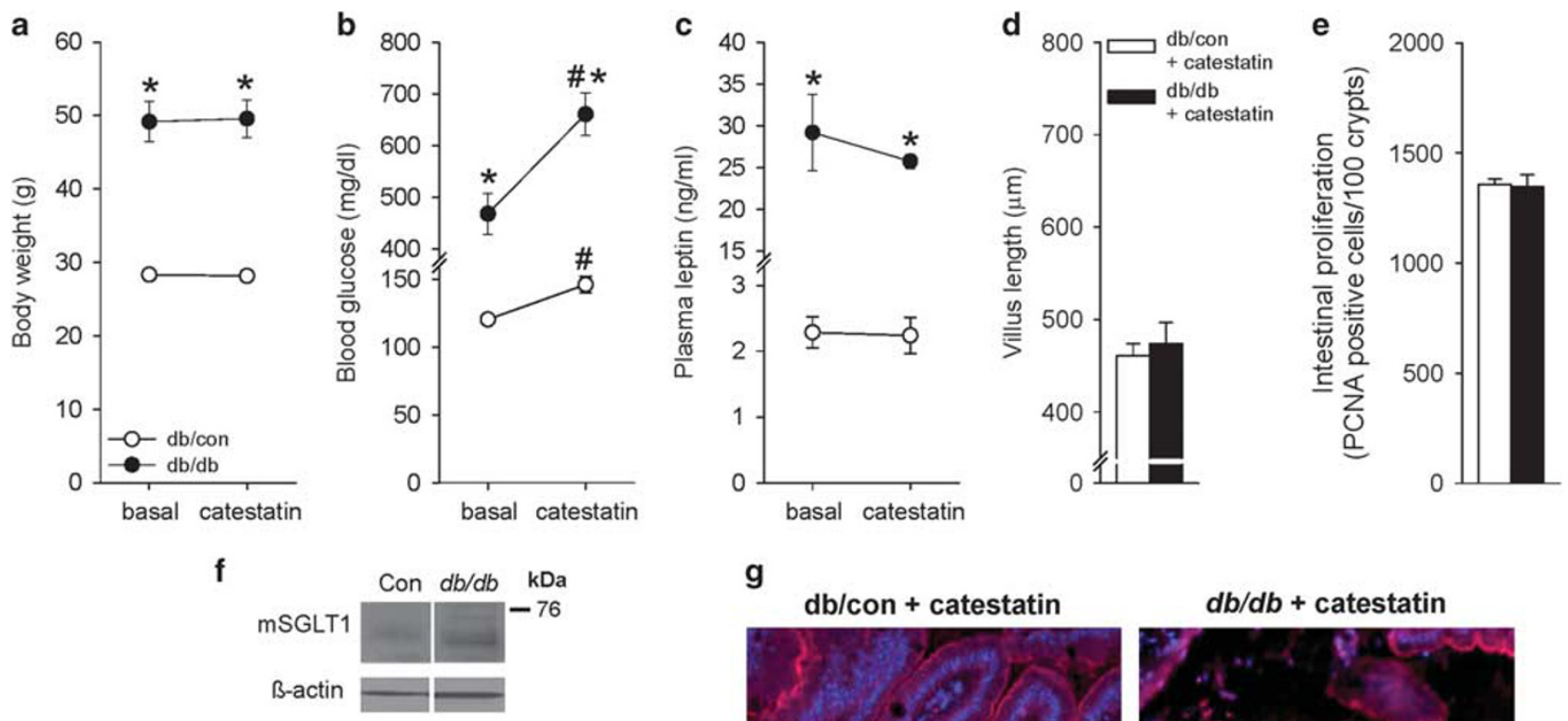

g
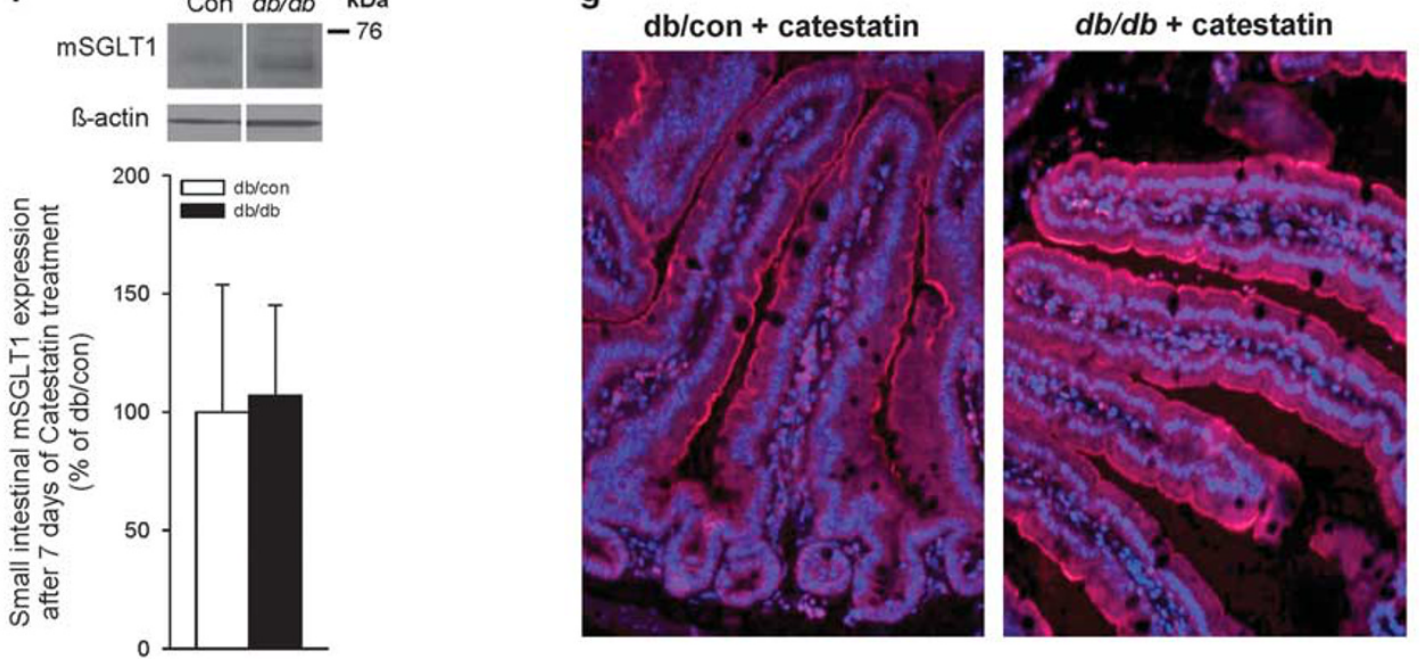

Figure 9 Inhibition of LEPRa via CST partially restores intestinal SGLT1 expression in hyperleptinemic mice. To test whether there is a possible interaction between CST and leptin in vivo, we treated mice hyperleptinemic ( $d b / d b)$ and control mice (db/con) for 7 days with CST (5 mg/kg) via daily i.p. injections. Inhibition of the short form of the leptin receptor (LEPRa) via treatment with CST had no effect on body weight (a) or plasma leptin levels

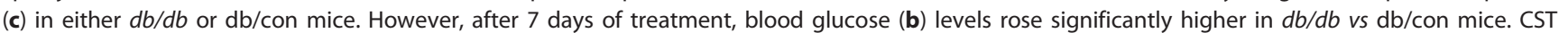
treatment resulted in normalization of villus length (d) and intestinal proliferation (e, proliferating cell nuclear antigen staining) in $d b / d b$ mice. For comparison of untreated $d b / d b$ and db/con mice, see Figures 2 and 3. In addition, CST treatment caused partial restoration of intestinal SGLT1 protein expression and membrane abundance ( $\mathbf{f}$ and $\mathbf{g}$ ) in $d b / d b$ mice. $N=4-5 /$ genotype. ${ }^{*} P<0.05 \mathrm{vs} \mathrm{db} / \mathrm{con},{ }^{*} P<0.05$ vs basal same genotype.

contrast, obese type 2 diabetic mice that lack endogenous leptin have unaltered intestinal SGLT1 membrane abundance. In the former, increased leptin signaling possibly via the short form of the leptin receptor, LEPRa, dampens the hyperglycemia of $d b / d b$ mice. However, CST, which mimics the binding site-III of leptin, possibly interferes with leptin signaling in $d b / d b$ mice and restores intestinal SGLT1 abundance and intestinal turnover.

Supplementary Information accompanies the paper on the Laboratory Investigation website (http://www.laboratoryinvestigation.org)

\section{ACKNOWLEDGMENTS}

We thank Maria Gerasimova, Chris Farrelly, and Samantha Chavez (APS STRIDE Undergraduate Summer Research Fellowship; 1 R25 HL115473-01) for their expert technical assistance. This work was supported by a Bastyr University Faculty Research Seed Grant (to JADR), Diabetes Endocrinology Research
Center P30DK063491 (to TR), American Heart Association 15BGIA22410018 (to TR), Satellite Healthcare, a not-for-profit renal care provider (to TR), and Department of Veterans Affairs Merit Review Award 5101BX000323-02 (to SKM).

\section{DISCLOSURE/CONFLICT OF INTEREST}

The authors declare no conflict of interest.

1. McCarthy MI. Genomics, type 2 diabetes, and obesity. N Engl J Med 2010;363:2339-2350.

2. Intagliata N, Koch KL. Gastroparesis in type 2 diabetes mellitus: prevalence, etiology, diagnosis, and treatment. Curr Gastroenterol Rep 2007;9:270-279.

3. Gorboulev V, Schurmann A, Vallon $V$ et al. $\mathrm{Na}(+)-D$-glucose cotransporter SGLT1 is pivotal for intestinal glucose absorption and glucose-dependent incretin secretion. Diabetes 2012;61:187-196.

4. Roder PV, Geillinger KE, Zietek TS et al. The role of SGLT1 and GLUT2 in intestinal glucose transport and sensing. PLoS One 2014;9:e89977. 
5. Burrin DG, Petersen Y, Stoll B et al. Glucagon-like peptide 2: a nutrientresponsive gut growth factor. J Nutr 2001;131:709-712.

6. Hirsh AJ, Tsang R, Kammila S et al. Effect of cholecystokinin and related peptides on jejunal transepithelial hexose transport in the SpragueDawley rat. Am J Physiol 1996;271:G755-G761.

7. El-Zein O, Kreydiyyeh SI. Leptin inhibits glucose intestinal absorption via PKC, p38MAPK, PI3K and MEK/ERK. PLoS One 2013;8:e83360.

8. Zhang $\mathrm{Y}$, Proenca $\mathrm{R}$, Maffei $\mathrm{M}$ et al. Positional cloning of the mouse obese gene and its human homologue. Nature 1994;372: 425-432.

9. Lee GH, Proenca R, Montez JM et al. Abnormal splicing of the leptin receptor in diabetic mice. Nature 1996;379:632-635.

10. Tartaglia LA, Dembski $M$, Weng $X$ et al. Identification and expression cloning of a leptin receptor, OB-R. Cell 1995;83:1263-1271.

11. Baumann $\mathrm{H}$, Morella KK, White DW et al. The full-length leptin receptor has signaling capabilities of interleukin 6-type cytokine receptors. Proc Natl Acad Sci USA 1996;93:8374-8378.

12. Hoggard N, Mercer JG, Rayner DV et al. Localization of leptin receptor mRNA splice variants in murine peripheral tissues by RT-PCR and in situ hybridization. Biochem Biophys Res Commun 1997;232: 383-387.

13. Mercer JG, Hoggard N, Williams LM et al. Localization of leptin receptor mRNA and the long form splice variant (Ob-Rb) in mouse hypothalamus and adjacent brain regions by in situ hybridization. FEBS Lett 1996;387:113-116.

14. Ghilardi N, Ziegler S, Wiestner A et al. Defective STAT signaling by the leptin receptor in diabetic mice. Proc Natl Acad Sci USA 1996;93: 6231-6235.

15. Lollmann B, Gruninger S, Stricker-Krongrad A et al. Detection and quantification of the leptin receptor splice variants Ob-Ra, b, and, e in different mouse tissues. Biochem Biophys Res Commun 1997;238: 648-652.

16. Wang B, Chandrasekera PC, Pippin JJ. Leptin- and leptin receptordeficient rodent models: relevance for human type 2 diabetes. Curr Diabetes Rev 2014;10:131-145.

17. Chen H, Charlat O, Tartaglia LA et al. Evidence that the diabetes gene encodes the leptin receptor: identification of a mutation in the leptin receptor gene in $\mathrm{db} / \mathrm{db}$ mice. Cell 1996;84: 491-495.

18. Li Z, Ceccarini G, Eisenstein M et al. Phenotypic effects of an induced mutation of the ObRa isoform of the leptin receptor. Mol Metab 2013:2:364-375.

19. Cammisotto PG, Levy E, Bukowiecki LJ et al. Cross-talk between adipose and gastric leptins for the control of food intake and energy metabolism. Prog Histochem Cytochem 2010;45: 143-200.

20. Yarandi SS, Hebbar G, Sauer CG et al. Diverse roles of leptin in the gastrointestinal tract: modulation of motility, absorption, growth, and inflammation. Nutrition 2011;27:269-275.

21. Mahata SK, Mahata M, Fung MM et al. Catestatin: a multifunctional peptide from chromogranin A. Regul Pept 2010;162:33-43.

22. Mahata SK, O'Connor DT, Mahata $M$ et al. Novel autocrine feedback control of catecholamine release. A discrete chromogranin A fragment is a noncompetitive nicotinic cholinergic antagonist. J Clin Invest 1997:100:1623-1633.

23. Mahata SK, Mahata M, Wen $G$ et al. The catecholamine releaseinhibitory "catestatin" fragment of chromogranin A: naturally occurring human variants with different potencies for multiple chromaffin cell nicotinic cholinergic responses. Mol Pharmacol 2004;66:1180-1191.

24. Bandyopadhyay GK, Vu CU, Gentile S et al. Catestatin (chromogranin A (352-372)) and novel effects on mobilization of fat from adipose tissue through regulation of adrenergic and leptin signaling. J Biol Chem 2012:287:23141-23151.

25. Khailova L, Frank DN, Dominguez JA et al. Probiotic administration reduces mortality and improves intestinal epithelial homeostasis in experimental sepsis. Anesthesiology 2013;119:166-177.

26. Rieg T, Tang T, Uchida $\mathrm{S}$ et al. Adenylyl cyclase 6 enhances NKCC2 expression and mediates vasopressin-induced phosphorylation of NKCC2 and NCC. Am J Pathol 2013;182:96-106.

27. Rieg T, Tang T, Murray F et al. Adenylate cyclase 6 determines CAMP formation and aquaporin-2 phosphorylation and trafficking in inner medulla. J Am Soc Nephrol 2010;21:2059-2068.
28. Dominguez JA, Samocha AJ, Liang Z et al. Inhibition of IKKbeta in enterocytes exacerbates sepsis-induced intestinal injury and worsens mortality. Crit Care Med 2013;41:e275-e285.

29. Preece NE, Nguyen $M$, Mahata $M$ et al. Conformational preferences and activities of peptides from the catecholamine releaseinhibitory (catestatin) region of chromogranin A. Regul Pept 2004;118: 75-87.

30. Zhang F, Basinski MB, Beals JM et al. Crystal structure of the obese protein leptin-E100. Nature 1997;387:206-209.

31. Eswar N, Webb B, Marti-Renom MA et al. Comparative protein structure modeling using Modeller. Curr Protoc Bioinformatics 2006;Chapter 5: Unit 5.6.

32. Carpenter B, Hemsworth GR, Wu Z et al. Structure of the human obesity receptor leptin-binding domain reveals the mechanism of leptin antagonism by a monoclonal antibody. Structure 2012;20: 487-497.

33. Peelman F, Van Beneden $K$, Zabeau L et al. Mapping of the leptin binding sites and design of a leptin antagonist. J Biol Chem 2004;279: 41038-41046.

34. Shi J, Blundell TL, Mizuguchi K. FUGUE: sequence-structure homology recognition using environment-specific substitution tables and structure-dependent gap penalties. J Mol Biol 2001;310: 243-257.

35. Hess B, Kutzner C, van der Spoel D et al. GROMACS 4: Algorithms for highly efficient, load-balanced, and scalable molecular simulation. J Chem Theory Comput 2008:4:435-447.

36. Hornak V, Abel R, Okur A et al. Comparison of multiple Amber force fields and development of improved protein backbone parameters. Proteins 2006;65:712-725.

37. Humphrey W, Dalke A, Schulten K. VMD: visual molecular dynamics. J Mol Graph 1996;14:33-38 27-38.

38. de Vries SJ, van Dijk M, Bonvin AM. The HADDOCK web server for datadriven biomolecular docking. Nat Protoc 2010;5:883-897.

39. Peelman F, Iserentant $\mathrm{H}$, De Smet AS et al. Mapping of binding site III in the leptin receptor and modeling of a hexameric leptin.leptin receptor complex. J Biol Chem 2006;281:15496-15504.

40. Rieg $T$, Masuda $T$, Gerasimova $M$ et al. Increase in SGLT1-mediated transport explains renal glucose reabsorption during genetic and pharmacological SGLT2 inhibition in euglycemia. Am J Physiol Renal Physiol 2014;306:F188-F193.

41. Buchan DW, Minneci F, Nugent TC et al. Scalable web services for the PSIPRED Protein Analysis Workbench. Nucleic Acids Res 2013;41: W349-W357.

42. Reidy $\mathrm{K}$, Kang HM, Hostetter T et al. Molecular mechanisms of diabetic kidney disease. J Clin Invest 2014;124:2333-2340.

43. Verdam FJ, Greve JW, Roosta $\mathrm{S}$ et al. Small intestinal alterations in severely obese hyperglycemic subjects. J Clin Endocrinol Metab 2011:96:E379-E383.

44. Adachi T, Mori C, Sakurai K et al. Morphological changes and increased sucrase and isomaltase activity in small intestines of insulin-deficient and type 2 diabetic rats. Endocr J 2003;50:271-279.

45. Alavi K, Schwartz MZ, Prasad R et al. Leptin: a new growth factor for the small intestine. J Pediatr Surg 2002;37:327-330.

46. Tavernier A, Cavin JB, Le Gall M et al. Intestinal deletion of leptin signaling alters activity of nutrient transporters and delayed the onset of obesity in mice. FASEB J 2014;28:4100-4110.

47. Hounnou G, Destrieux C, Desme J et al. Anatomical study of the length of the human intestine. Surg Radiol Anat 2002;24:290-294.

48. Kiely JM, Noh JH, Pitt HA et al. Impaired intestinal cell proliferation and cell death in leptin-deficient obese mice. JPEN J Parenter Enteral Nutr 2005;29:30-35.

49. Barrenetxe J, Villaro AC, Guembe $L$ et al. Distribution of the long leptin receptor isoform in brush border, basolateral membrane, and cytoplasm of enterocytes. Gut 2002;50:797-802.

50. Lu FL, Johnston RA, Flynt $\mathrm{L}$ et al. Increased pulmonary responses to acute ozone exposure in obese $\mathrm{db} / \mathrm{db}$ mice. Am J Physiol Lung Cell Mol Physiol 2006;290:L856-L865.

51. Sakar Y, Nazaret $C$, Letteron $\mathrm{P}$ et al. Positive regulatory control loop between gut leptin and intestinal GLUT2/GLUT5 transporters links to hepatic metabolic functions in rodents. PLoS One 2009:4:e7935.

52. Ducroc R, Guilmeau S, Akasbi K et al. Luminal leptin induces rapid inhibition of active intestinal absorption of glucose mediated by sodium-glucose cotransporter 1. Diabetes 2005;54:348-354. 
53. Morton NM, Emilsson V, Liu YL et al. Leptin action in intestinal cells. J Biol Chem 1998;273:26194-26201.

54. Mao J, Hu X, Xiao Y et al. Overnutrition stimulates intestinal epithelium proliferation through beta-catenin signaling in obese mice. Diabetes 2013;62:3736-3746.

55. Leung L, Kang J, Rayyan E et al. Decreased basal chloride secretion and altered cystic fibrosis transmembrane conductance regulatory protein, Villin, GLUT5 protein expression in jejunum from leptin-deficient mice. Diabetes Metab Syndr Obes 2014;7:321-330.

56. Niv-Spector L, Gonen-Berger D, Gourdou I et al. Identification of the hydrophobic strand in the A-B loop of leptin as major binding site III: implications for large-scale preparation of potent recombi- nant human and ovine leptin antagonists. Biochem J 2005;391: 221-230.

57. Van Heek M, Compton DS, France CF et al. Diet-induced obese mice develop peripheral, but not central, resistance to leptin. J Clin Invest 1997;99:385-390.

58. Bacart J, Leloire A, Levoye A et al. Evidence for leptin receptor isoforms heteromerization at the cell surface. FEBS Lett 2010;584:2213-2217.

59. White DW, Tartaglia LA. Evidence for ligand-independent homooligomerization of leptin receptor (OB-R) isoforms: a proposed mechanism permitting productive long-form signaling in the presence of excess short-form expression. J Cell Biochem 1999;73: 278-288. 